\title{
Exploring Antioxidant Potential of Some Common Marketed Non- Steroidal Anti-Inflammatory Drugs
}

\section{Payel Ghosh, Shatavisa Mukherjee*, Chowdhury M Hossain, Pranabesh Chakrabarty}

Department of Pharmaceutical Technology, Bengal School of Technology, Sugandha, West Bengal, India.

*Corresponding author: Shatavisa Mukherjee, Department of Pharmaceutical Technology, Bengal School of Technology, Sugandha, West Bengal, India, E-mail: shatavisa100@gmail.com

Received: April 05, 2017; Revised: July 10, 2017; Published: August 11, 2017

Copyright: (C2017 Ghosh P, et al. This is an open-access article distributed under the terms of the Creative Commons Attribution License, which permits unrestricted use, distribution, and reproduction in any medium, provided the original author and source are credited. The article has been previewed and authenticated by the Authors before sending the publication for print. The Journal, Editor and the Editorial Board are not entitled or liable to either justify or responsible for inaccurate and misleading data if any. It is the sole responsibility of the Author concerned.

Citation: Ghosh P, Mukherjee S, Hossain CM, et al. Exploring Antioxidant Potential of Some Common Marketed Non-Steroidal Anti-Inflammatory Drugs. Int J Pharm Pharmacol 2017; 1: 112. doi: $\underline{10.31531 / 2581-3080.1000112}$

\begin{abstract}
Considerable controversy exists on the effect of NSAIDs on the oxidative status. Despite being held pro-oxidant in few instances, there are many studies which have commented on the antioxidant effect of NSAIDs and its relevance and beneficial utilization in clinical set-up. The present study probed into the antioxidant potential of some common marketed NSAIDs in in-vitro set up using DPPH and Nitric oxide radical scavenging assay. Nitric oxide radical scavenging procedure showed maximum scavenging activity for paracetamol and mefenamic acid, followed by aspirin. Results from DPPH assay showed maximum scavenging activity from aspirin followed by ibuprofen. Other NSAIDs also showed considerable radical scavenging activity indicative of antioxidant potential.
\end{abstract}

Keywords: Antioxidant, DPPH assay, Nitric oxide radical scavenging activity, NSAIDs

\section{Introduction}

Reactive oxygen species (ROS), along with reactive nitrogen species (RNS), may play an important role in the pathogenesis and progressing of many diseases. The cumulative production of ROS/RNS through either endogenous or exogenous insults is termed as oxidative stress which contributes to pathological conditions like inflammatory tissue injuries, which are mediated by reactive oxygen metabolites from phagocytic leukocytes invading the tissue. These reactive radicals and oxidants may injure cells and tissue directly via oxidative degradation of essential cellular components or indirectly by altering the protease/anti-protease balance that normally exists within the intestinal tissue [1]. Oxidative stress results in direct or indirect ROSmediated damage of nucleic acids, proteins, and lipids and has been significantly implicated in conditions like carcinogenesis, 
neurodegeneration, atherosclerosis, diabetes, and aging. However, ROS involvement in the pathogenesis of disease states is not confined to macromolecular damage.

ROS levels and the redox state of a cell are considered to be important in the dysfunction of various biological signalling pathways. The formation of ROS via the reduction of molecular oxygen or by the oxidation of water leads to the formation of free radicals such as superoxide anion, hydroxyl radical, and hydrogen peroxide. Oxidative stress arises when the oxidant production surpasses the antioxidant capacity in the cells. NSAIDs have been shown to be associated with increased ROS production. NSAIDs has been the most widely used over-the-counter drugs as well as the most prescribed class of drugs for a variety of conditions including pains, rheumatoid arthritis, osteoarthritis, musculoskeletal disorders, and other comorbid conditions [2]. Previous research has shown that well known NSAIDs yields major substances with antiinflammatory property. Since antioxidant activity of substances may have an important role in their anti-inflammatory and antiproliferative activities, the aim of this work was to determine the antioxidant properties of some common marketed NSAIDs in an in-vitro setup. The objective of the study was to screen antioxidant activity of commonly marketed NSAID preparations in various therapeutic concentrations through processes like DPPH assay and Nitric oxide scavenging activity.

\section{Materials and Methods}

Marketed tablet formulations of different NSAIDs class viz Aspirin 75 mg [Ecospirin-75 (USV Ltd)], Mefenamic acid [Meftal-Spas (Blue Cross)], Diclofenac $50 \mathrm{mg}$ [Voveran 50 (Novartis)], Ibuprofen $400 \mathrm{mg}$ [Brufen 400 (Abbot India Ltd)], Paracetamol 500mg [Doliprane 500 (Ankur Drugs and Pharma Ltd)] and Indomethacin $25 \mathrm{mg}$ [Indocap (Jagsonpal Pharmaceuticals Ltd.)] were obtained and different concentrations of these tablets extrapolated from attainable human therapeutic plasma concentrations were prepared.
Antioxidant property of the various concentrations of the prepared sample was measured using standard in-vitro radical scavenging assays like DPPH assay, Nitric oxide radical scavenging assay.

\section{DPPH Assay}

$0.1 \mathrm{mM}$ solution of DPPH in methanol was prepared \& $1 \mathrm{ml}$ of this solution was added to 3 $\mathrm{ml}$ of various concentrations prepared sample. After $30 \mathrm{~min}$, absorbance was measured at 517 $\mathrm{nm}$. The percentage of inhibition was calculated by comparing the absorbance value of control and test sample. Ascorbic acid was used as a reference compound [3].

The capability to scavenge the DPPH radical was calculated using this equation:

\section{\%inhibition $=\left(A_{C}-A_{E}\right) / A_{B} \times 100$}

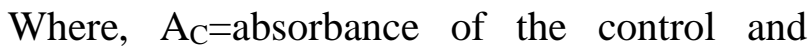
$\mathrm{A}_{\mathrm{E}}=\mathrm{absorbance}$ of tested samples.

\section{Nitric Oxide Radical (NO-) Scavenging Activity}

The procedure is based on the principle that, sodium nitroprusside in aqueous solution at physiological $\mathrm{pH}$ spontaneously generates nitric oxide which interacts with oxygen to produce nitrite ions that can be estimated using Greiss reagent. Scavengers of nitric oxide compete with oxygen, leading to reduced production of nitrite ions [4].

Sodium nitroprusside $(5 \mathrm{mM})$ in phosphate buffered saline (PBS) was mixed with $3.0 \mathrm{mi}$ of different concentration of tablet solution and incubate at $25^{\circ} \mathrm{C}$ for $150 \mathrm{~min}$. The sample from the above were reacted with Griess reagent (1\% sulphanilamide, $2 \% \quad \mathrm{H}_{3} \mathrm{PO}_{4}, 0.1 \%$ napthylethylenediamine dihydrochloride). The absorbance was measured at $546 \mathrm{~nm}$. Ascorbic acid was used as reference compound.

The $\%$ inhibition was calculated as:

\% NO scavenging activity = [Absorbance of
control - Absorbance of test
sample/Absorbance of control] X 100

\section{Results}


Percentage radical scavenging activity as a measure of antioxidant potential was assessed for the various concentrations of common marketed NSAIDs like aspirin, paracetamol, ibuprofen, indomethacin, mefenamic acid and diclofenac. Results from both nitric oxide radical scavenging activity and DPPH assay are tabulated in Table 1 and Table 2 respectively. Nitric oxide radical scavenging procedure showed maximum scavenging activity for paracetamol $25 \mathrm{mcg} / \mathrm{ml}$ and mefenamic acid 20 $\mathrm{mcg} / \mathrm{ml}$, followed by aspirin $300 \mathrm{mcg} / \mathrm{ml}$.

Results from DPPH assay showed maximum scavenging activity from aspirin $300 \mathrm{mcg} / \mathrm{ml}$ followed by ibuprofen $100 \mathrm{mcg} / \mathrm{ml}$. Other NSAIDs also showed considerable radical scavenging activity indicative of antioxidant potential.

\section{Discussion}

From treating conditions like rheumatoid arthritis, osteoarthritis, gout, menstrual pain, headache/migraine, post-operative pain, physical injury, ileus, renal colic to being used for antiplatelet effect, NSAIDs are amongst most common class of medications prescribed globally. Various analgesic and antiinflammatory agents from natural sources are known to possess antioxidant potential, which thereby aids in its beneficial utilization. An antioxidant is a molecule that inhibits the oxidation of other molecules that can produce free radicals, leading to chain reactions that may damage cells. Antioxidants such as thiols or ascorbic acid (vitamin C) terminate these chain reactions. Plants and animals maintain complex systems of overlapping antioxidants, such as glutathione and enzymes (e.g., catalase and superoxide dismutase) produced internally or the dietary antioxidants, vitamin A, vitamin $\mathrm{C}$ and vitamin $\mathrm{E}$. Various procedures which can estimate the free radical scavenging activity or the antioxidant potential of a compound includes: DPPH assay, Hydrogen peroxide radical scavenging activity assay, Nitric oxide radical (NO-) scavenging activity and Superoxide radical scavenging activity. The present study explored antioxidant potential of some common marketed NSAIDs using DPPH assay and Nitric oxide radical scavenging activity.
Common NSAIDs from various classes like aspirin, paracetamol, ibuprofen, indomethacin, mefenamic acid and diclofenac were adjudged in-vitro for their radical scavenging potential indicative of antioxidant effect. Previous studies have conferred that aspirin exhibited a protective effect against silica-induced lipid peroxidation and DNA strand breakage [5]. Various results showed that aspirin functions as an antioxidant via its ability to scavenge $* \mathrm{OH}$ radicals. In our present study, aspirin at 300 $\mathrm{mcg} / \mathrm{ml}$ showed maximum radical scavenging activity, though DPPH assay in comparison to other NSAIDs of various classes. Ibuprofen, one of the most sold over-the-counter NSAIDs possesses potential effect as oxidative stress and endocrine disruption inducer as identified in studies [6]. The present study showed that ibuprofen exhibiting considerably higher radical scavenging potentials at $100 \mathrm{mcg} / \mathrm{ml}$. Paracetamol at concentration of $25 \mathrm{mcg} / \mathrm{ml}$ and mefenamic acid at $20 \mathrm{mcg} / \mathrm{ml}$ showed maximum radical scavenging potential in comparison to ascorbic acid taken as standard. Some scavenging properties have been also reported for diclofenac. Studies have inferred inhibition of both phosphatidylcholine liposomes oxidation and linoleic acid peroxidation. Diclofenac is known to protect human erythrocytes against hemolysis process induced by peroxyl radicals [7]. All these reports are suggestive of antioxidant potential of this drug.

On a practical note, several NSAIDs administered to rats simultaneously with ethanol diminished some indicators of liver damage promoted by this hepatotoxic compound. The use of NSAIDs like aspirin, naproxen, nimesulide, and piroxicam partially reversed the increase in triglycerides and thiobarbituric acid-reactant substances as well as the decrease in reduced and total glutathione produced by acute ethanol intoxication [8-10]. NSAIDs have also demonstrated delay in onset and progression of Alzheimer's disease. NSAIDs are reported to neutralize the destructive hydroxyl free radicals. In the human body, this could also prevent radical mediated neurotoxic cell death and hinder the formation of neuritic plaques in the brain [11]. Despite conflicting studies stating NSAIDs as a prooxidant also [12,13], radical scavenging 
potential [14] of commonly used NSAIDs preparation to an extent outweighs the risk. However further research on this arena will be of prime importance in clinical domain.

\section{Conclusion}

Antioxidant may be added to the pharmaceutical preparations to inhibiting the oxidative decomposition or controlling the free radical formation Antioxidant potential of various compounds has been studied of late. The present study probed into the antioxidant potential of some common marketed NSAIDs in in-vitro set up. Results from this study concludes that various classes of NSAIDs has potential antioxidant property as observed from both assay techniques and can have some promising clinical implications for these.

\section{Source of Support}

Nil.

\section{Conflict of Interest}

None declared.

\section{References}

1. Son SM. Reactive Oxygen and Nitrogen Species in Pathogenesis of Vascular Complications of Diabetes. Diabetes Metab J 2012; 36: 190-198.

2. Ghosh R, Alajbegovic A, Gomes AV. NSAIDs and Cardiovascular Diseases: Role of Reactive Oxygen Species. Oxid Med Cell Longev 2015; 536962.

3. Brand-Williams W, Cuvelier ME, Berset C. Use of a free radical method to evaluate antioxidant activity. Lebenson Wiss Technol 1995; 28: 25-30.

4. Marcocci L, Maguire JJ, Droy-Lefaix MT, Packer L. The nitric oxide scavenging properties of Ginkgo biloba extract EGb761. Biochem Biophys Res Commun 1994; 201: 748-755.

5. Shi X, Ding M, Dond Z, et al. Antioxidant properties of aspirin: characterization of the ability of aspirin to inhibit silica-induced lipid peroxidation, DNA damage, NF- $\kappa \mathrm{B}$ activation, and TNF- $\alpha$ production. Mol Cell Biochem 1999; 199: 93-102.

6. Gonzalez-Rey M, Bebianno MJ. Does NonSteroidal Anti-Inflammatory (NSAID) Ibuprofen Induce Antioxidant Stress and Endocrine Disruption in Mussel Mytilus Galloprovincialis? Environ Toxicol Pharmacol 2011; 33: 361-371.

7. Salama A, Kroll H, Wittmann G, et al. Diclofenac-induced immune haemolytic anaemia: simultaneous occurrence of red blood cell autoantibodies and drugdependent antibodies. Br J Haematol 1996; 95: 640-644.

8. Zentella de Piña M, Hernández-Tobías A, SaldañaBalmori $Y$, et al. Biochemical ethanol effects affected by a non-steroidal anti-inflammatory drug. FEBS Lett 1992; 298: 123-125.

9. Zentella de Piña M, Saldaña-Balmori Y, HernándezTobías A, et al. Nonsteroidal anti-inflammatory drugs lower ethanolmediated liver increase in lipids and thiobarbituric acid reactive substances. Alcohol Clin Exp Res 1993; 7: 1228-1232.

10. Zentella de Piña M, Corona S, RochaHernández A, et al. Restoration by piroxicam of liver glutathione levels decreased by acute ethanol intoxication. Life Sci 1994; 54: 1433- 1439.

11. Basu S. Theorized Mechanism of NonSteroidal Anti-Inflammatory Drugs against Alzheimer's disease Onset and Progression. J Young Invist 2001; 3: 1-2.

12. Wallace JL, Granger DN. Pathogenesis of NSAID gastropathy: are neutrophils the culprits. Trends Pharmacol Sci 1992; 13: 129-131.

13. Hickey EJ, Raje RR, Reid VE, et al. Diclofenac- induced in vivo nephrotoxicity may involve oxidative stress-mediated massive genomic DNA fragmentation and apoptotic cell death. Free Radic Biol Med 2001; 31: 139-152.

14. Litvinova NV, Kurapova TN. The nonsteroidal anti-inflammatory drugs: possible mechanisms of antioxidant action. Biopolym. Cell 2004; 20: 472-478. 
Table 1: Nitric Oxide Radical (NO-) Scavenging Activity

\begin{tabular}{|c|c|c|c|}
\hline Sl. No. & Drug & Concentration (mcg/ml) & \% Scavenging Activity \\
\hline 1 & Vitamin C (Standard) & 100 & 89.20 \\
\hline 2 & Aspirin (75 mg) & 150 & 66.18 \\
\hline & & 200 & 61.18 \\
\hline & & 250 & 61.7 \\
\hline & & 300 & 80.5 \\
\hline 3 & Paracetamol (500 mg) & 10 & 56.8 \\
\hline & & 15 & 58.9 \\
\hline & & 20 & 81.2 \\
\hline & & 25 & 86.3 \\
\hline 4 & Ibuprofen (400 mg) & 25 & 51.0 \\
\hline & & 50 & 53.2 \\
\hline & & 75 & 54.6 \\
\hline & & 100 & 58.2 \\
\hline 5 & Indomethacin & 1 & 39.5 \\
\hline & & 1.5 & 42.4 \\
\hline & & 2.5 & 48.9 \\
\hline & & 3 & 48.9 \\
\hline 6 & Mefenamic Acid & 10 & 54.67 \\
\hline & & 15 & 59.71 \\
\hline & & 20 & 86.3 \\
\hline & & 1 & 27.3 \\
\hline & & 2 & 38.1 \\
\hline & & 3 & 47.4 \\
\hline & & 4 & 59.7 \\
\hline
\end{tabular}

Table 2: DPPH Assay

\begin{tabular}{|c|c|c|c|}
\hline Sl. No. & Drug & Concentration $\mathbf{( m c g} / \mathbf{m l})$ & \% Scavenging Activity \\
\hline 1 & Vitamin C (Standard) & 100 & 80.2 \\
\hline 2 & Aspirin (75 mg) & 150 & 68.9 \\
\hline & & 200 & 70.6 \\
\hline & & 250 & 71.1 \\
\hline & & 300 & 71.7 \\
\hline 3 & Paracetamol (500 mg) & 10 & 48.5 \\
\hline & & 15 & 51.4 \\
\hline & & 20 & 51.9 \\
\hline & & 25 & 52.5 \\
\hline 4 & Ibuprofen (400 mg) & 25 & 60.4 \\
\hline & & 50 & 61.5 \\
\hline & & 75 & 63.2 \\
\hline & & 100 & 64.4 \\
\hline 5 & Indomethacin & 1 & 50.8 \\
\hline
\end{tabular}




\begin{tabular}{|c|c|c|c|}
\hline & & 1.5 & 51.4 \\
\hline & & 2.5 & 54.2 \\
\hline & & 3 & 55.9 \\
\hline 6 & Mefenamic Acid & 10 & 50.8 \\
\hline & & 15 & 53.1 \\
\hline & & 20 & 53.6 \\
\hline 7 & Diclofenac & 1 & 50.8 \\
\hline & & 2 & 51.4 \\
\hline & & 3 & 53.1 \\
\hline & & 4 & 53.6 \\
\hline
\end{tabular}


This manuscript was peer-reviewed

Mode of Review: Single-blinded

Editor: Dr. Abdur Rauf

International Journal of Pharmaceutics and Pharmacology is an open access, peer reviewed journal published by Edwiser International.

Submit your valuable manuscript at-

editor.ijpp@edwiserinternational.com

submit.manuscript@edwiserinternational.com

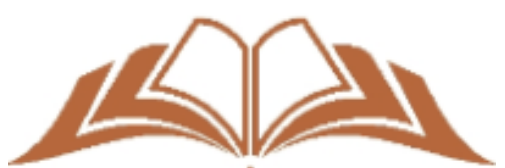

EDW $\mathrm{W}$ S E R
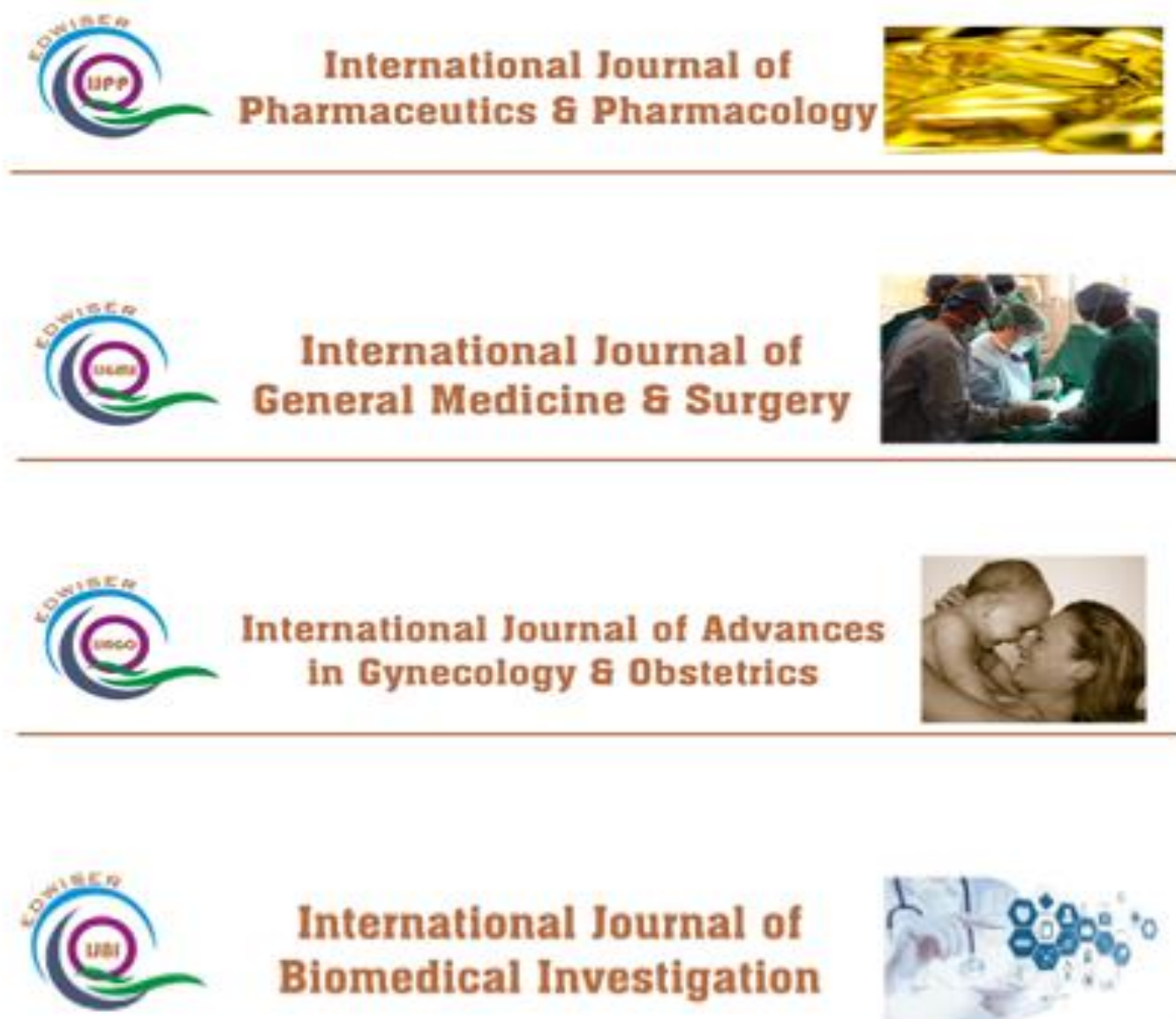

\section{International Journal of Biomedical Investigation}
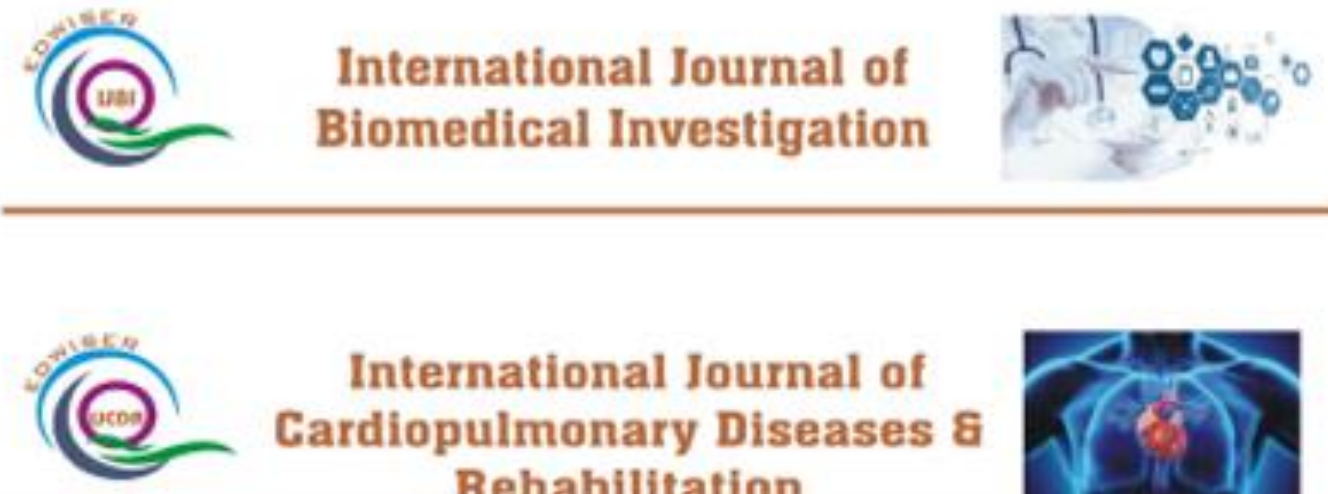

International Journal of Cardiopulmonary Diseases \& Rehabilitation

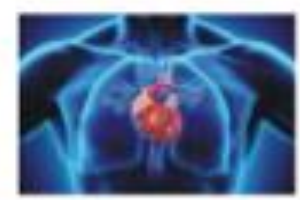

